\title{
Correspondence
}

\section{Anaesthesia and emesis. Clinical usefulness of metoclopramide}

To the Editor:

In the otherwise excellent review article "Anaesthesia and emesis, II" by Palazzo and Strunin, 'the section devoted to metoclopramide is perhaps open to comment.

Reference is made to Davies and Howells' paper on the ability of metoclopramide to empty the stomach following injury, ${ }^{2}$ which did not differentiate between liquid and solid gastric content. Hancock ${ }^{3}$ showed no difference in gastric emptying times in normal subjects following a solid meal when they were given a placebo or metoclopramide. It is suggested that this is an important difference which should be taken into consideration by the anaesthetist who is faced with a patient with a full stomach. Liquid gastric content may be reduced but solid contents will not.

The authors claim that metoclopramide and domperidone have not proven to be effective in either prophylaxis or treatment of postoperative vomiting and refer, among others, to the work of Clark and Storrs ${ }^{4}$ who in fact showed a significant reduction ( $p=0.05$ ) in postoperative vomiting after metoclopramide $20 \mathrm{mg}$.

A number of investigators have in fact found metoclopramide to be effective in the treatment and prophylaxis of postoperative vomiting. ${ }^{5-9}$

There are two properties of metoclopramide which the authors did not discuss. Firstly the more potent action in males compared to females. This was published as raw data by Kreel and Howells ${ }^{10}$ but not referred to in the paper and also by Diamond and Keeri-Szanto " who showed a significant reduction in postoperative vomiting in males by prophylaxis with metoclopramide ( $\mathrm{p}$ much less than 0.001 ) as compared to females in a similar surgical group (N.S.)
Secondly, is the question of the freedom from side effects of this drug, which has best been illustrated by Gralla et al. ${ }^{12}$ who gave metoclopramide $120 \mathrm{mg}$ at two hourly intervals over a ten hour period to patients undergoing Cisplatin chemotherapy. This resulted in a significant reduction in emesis when compared to placebo administration ( $p=0.001)$ or to prochlorperazine administration ( $p=0.005)$. The follow-up of 450 patients undergoing this regimen revealed acute dystonic reactions in only 3.1 per cent of the patients. ${ }^{13}$

It would appear that the recommendations of the authors of the review article to use another agent should a single dose of metoclopramide not prove effective is not borne out in the literature.

The Sloan-Kettering Experience suggests strongly that over a short period of time, high doses of metoclopramide are well tolerated, but the longterm effect of therapy may lead to extra pyramidal side effects.

\section{Michael J. Diamond MB FRCP(C)}

Department of Anaesthesia

University of Western Ontario

London, Ontario

REFERENCES

1 Palazzo MGA, Strunin L. Anaesthesia and cmesis: Prevention and management. Can Anaesth Soc J 1984; 31: 407-15.

2 Davies JAH, Howells TH. Management of the full stomach case in the casualty department. Postgrad Med J 1973 (Suppl) 58-63.

3 Hancock BD, Bowen-Jones $E$ et al. The effect of metoclopramide on gastric emptying of solid meals. Gut $1974 ; 15$ : 402-67.

4 Clark MM, Storrs JA. The prevention of postoperative vomiting after abortion: Metoclopramide. $\mathrm{Br} \mathrm{J}$ Anaesth 1969; $41: 890$.

5 Assaf RAE, Clarke RSJ, Dundee JW, Samuel JO. Studies of drugs given before anaesthesia. XXIV. Metoclopramide with morphine and Pethidine. $\mathrm{Br} \mathrm{J}$ Anaesth 1974; 46: 514 .

6 Baver A. Antiemetic effect of metoclopramide in connection with surgery. Vichy Symposium on Gastroduodenal Dyskinesia, 1966. 
7 Dundee JW, Clarke RSJ. The premedicant and antiemetic action of metoclopramide. Postgrad Med J 1973 (Suppl) 34.

8 Handley AJ. Metoclopramide in the prevention of postoperative nausea and vomiting. Br J Clin Pract 1967; 21: 9, 460-2.

9 Lind $B$, Breivik $H$. Metoclopramidc and perphenezine in the prevention of postoperative nausea and vomiting. Br J Anaesth 1970; 42: 7.

10 Kreel L, Trott M, Howells TH. The influence of oral metoclopramide on gastric emptying after affixed water load. Clin Radiol 1972; 23: 213.

11 Diamond MJ, Keeri-Szanto M. Reduction of postoperative vomiting by preoperative administration of oral metoclopramide. Can Anaesth Soc J 1980; 27: 36-9.

12 Gralla RJ, Itri LM, Pisko SC et al. Antiemetic efficacy of high dose Metoclopramide: Randomized trials with placebo and prochlorperazine in patients with chemothcrapy induced nausea and vomiting. N Engl J Med 1981; 305: 905-9.

13 Gralla RJ, Itri LM, Pisko SC et al. Extrapyramidal reactions with high dose metoclopramide, $N$ Engl J Med 1983; 309: 433.

\section{$R E P L Y$}

Thank you for giving us the opportunity to reply to the points raised by $D r$. Diamond concerning our review article Anaesthesia and emesis, $I I$.

Dr. Diamond is correct to point out that the action of metoclopramide on stomach emptying can be quite variable and it is seemingly ineffective following a solid meal.' However, for the purposes of emergency anaesthesia the maller becomes academic. As our article suggests, we prefer the popular and efficient Sellick manoeuvre for the prevention of a spiration and would not rely on metoclopramide to empty the stomach.

Attention is drawn to our apprasial of the efficacy of metoclopramide for prevention and treatment of pastoperative emesis. We referred to the work of Clark and Storrs which demonstrated that $20 \mathrm{mg}$ of metoclopramide administered at the end of surgery was efficient in decreasing postoperative emesis. ${ }^{2}$ This work was supported by Lind and Breivik who found that in patients who had not received meperidine (the only comparable patients in their subgroups), $10 \mathrm{mg}$ of metoclopramide given $I M$ at the end of surgery reduced retching and vomiting better than did perphenazine. Note that nausea was not recorded in this subgroup of their study. ${ }^{3}$ Handley and Tornetta in independent studies also found metoclopramide usefut when given at the end of surgery. ${ }^{4,5}$ However, Diamond's own work dernonstrated that $20 \mathrm{mg}$ metoclopramide given orally two hours preoperatively with the premedication to 51 patients undergoing hysterectomy had no significant effect. Also in the same study, females undergoing non-abdominal surgery were also not helped by preoperative metoclopramide. ${ }^{6}$ These data confirmed wark by Assaf et al. who showed that preoperative I.M. metoclopramide did not significantly reduce total emetic sequelae in the 1-6-hour period when the premedication included morphine. ${ }^{7}$ Ellis and Shaw in separate studies also had poor results with preoperative metoclopramide. ${ }^{8,9}$

We therefore think it reasonable to state "prophylaxis with metoclopramide appears to only have been effective when the drug was administered at the end of the operation." Evidence suggests that metoclopramide is a poor drug for the tratment of emesis. ${ }^{10}$ It follows from the above that if metoclopramide has been given for prophylaxis against emesis and has failed, it would be logical to administer a drug with proven efficacy for the treatment of the now new problem of emesis.

We confess to omitting reference to the poorer effect of metoclopramide in women than among men. This may explain some of the variable results in clinical trials and would be a good reason not to use metoclopramide.

We agree with $D r$. Diamond that side effects from the use of metoclopramide are low. We stated: "all studies report a low incidence of side effects with both domperidone and metoclopramide." We have no experience in the use of high dose metoclopramide, but should point out that the incidence of side effects is considerably higher in the under 30 age group, 27.3 per cent according to Kris et al." Further we would suggest that cancer therapy patients may behave differently to postanaesthetic patients and comparison may not be appropriate.

There is no single obvious solution to postoperative emesis. Its mutifactorial aeteology makes it almost impassible to conduct completely controlled clinical trials. It is not surprising that anaesthetists working under diverse conditions achieve similar results with their differing but preferred methods and drugs. If Dr. Diamond achieves good results with his techniques and metoclopramide we hope our article has not discouraged him.

M.G.A. Palazzo MB ChB MRCP fFarCS

Leo Strunin MD FFARCS FRCP(C)

Department of Anaesthesia

Foothills Hospital at the University of Calgary

Calgary, Alberta

\section{REFERENCES}

1 Hancock BD, Bowen-Jones E, Dixon R, Dymock $I W$, Cowley DJ. The effect of metoclopramide on gastric emptying of solid meals. Gut 1974; 15: $402-67$.

2 Clark MM, Storrs JA. The prevention of postoperative vomiting after abortion: Metoclopramide. Br J Anaesth 1969; 41: 890-2.

3 Lind B, Breivik $H$. Metoclopramide and perphenazine in the prevention of postoperative nausea and vomiting. $\mathrm{Br} J$ Anaesth $1970 ; 42: 614-7$.

4 Handley $A J$. Metoclopramide in the prevention of postoperative nausea and vomiting. $\mathrm{Br} \mathrm{J}$ Clin Pract 1967;21: 460-2. 